GU J Sci, Part C, 6(3): 544-557 (2018)

Gazi Üniversitesi
Fen Bilimleri Dergisi
PART C: TASARIM VE TEKNOLOJI
dergipark.gov.tr/http-gujsc-gazi-edu-tr

\title{
Metal-Gözenekli Silisyum Direkt Hidrojen Pili Üretim Parametrelerinin Geliştirilmesi
}

\author{
Sevinç GÜLER ${ }^{1}$, Çiğdem ORUÇ ${ }^{2, *}$, Hüseyin Murat LUŞ ${ }^{3}$ \\ ${ }^{I}$ Nişantaşı Üniversitesi, Meslek Yüksek Okulu, Tıbbi Hizmetler ve Teknikler Bölümü, Sarlyer/ISTANBUL \\ ${ }^{2}$ Yıldız Teknik Üniversitesi, Fen-Edebiyat Fakültesi, Fizik Bölümü, 34220, Esenler/ISTANBUL \\ ${ }^{3}$ Yıldız Teknik Üniversitesi, Kimya-Metalurji Fakültesi, Metalurji ve Malzeme Mühendisliği Bölümü, 34220, Esenler/ISSTANBUL
}

\begin{abstract}
$\ddot{O} z$
Makale Bilgisi

Basvuru: 24/01/2018

Düzeltme: 28/06/2018

Kabul: 02/07/2018

Anahtar Kelimeler

Gözenekli Silisyum Anodizasyon Koşulları Hidrojen Pili

Gözenekli silisyum (GS) üretim yöntemi olan, elektrokimyasal aşındırma (anodizasyon) koşullarının, Metal-Gözenekli Silisyum Direkt Hidrojen Pili (Metal-GS-DHP) elektriksel parametrelerine etkisi oldukça yüksektir. Bu çalışmada üretilen, n tipi, (111) yönelimli, tek kristal silisyumdan GS'nin 4 temel anodizasyon koşulu vardır (zaman, akım yoğunluğu, HF oranı ve Işık aydınlatma). Anodizasyon zamanı 5-100 dakika, akım yoğunluğu 5-75 $\mathrm{mA} / \mathrm{cm}^{2}$, HF:deiyonize $\mathrm{H}_{2} \mathrm{O}$ oranı 1:1- 1:11 ve 1şık aydınlatma şiddeti 1000-7000 lüx aralıklarında uygulanmıştır .En iyi anodizasyon zamanı 40 dakika ve buna karşıllk gelen Metal-GS-DHP elektriksel pil parametreleri, Voc $=590 \mathrm{mV}$ Isc=30 $\mu$ A'dir. En iyi akım yoğunluğu $20 \mathrm{~mA} / \mathrm{cm}^{2}$ ve buna karşılık gelen Metal-GS-DHP elektriksel pil parametreleri, Voc $=700 \mathrm{mV}$, Isc $=15$ $\mu \mathrm{A}$ 'dir. En iyi $\mathrm{HF}: \mathrm{H}_{2} \mathrm{O}$ oranı 1:3 ve buna karşılık gelen Metal-GS-DHP elektriksel pil parametreleri, Voc $=420 \mathrm{mV}$, Isc=10 $\mu \mathrm{A}^{\prime}$ dir. En iyi 1şı aydınlatma şiddeti 4000 lüx ve buna karş1lı gelen Metal-GS-DHP elektriksel pil parametreleri, Voc $=540 \mathrm{mV}$ Isc $=18 \mu$ A'dir. Deney sonuçlarından anlaşılacağı üzere Metal-GS-DHP elektriksel pil parametreleri anodizasyon koşullarına direkt bağlıdır.
\end{abstract}

Keywords

Porous Silicon Anodization Parameters Hydrogen Cell

\section{Development of Metal-Porous Silicon Direct Hydrogen Fuel-Cell Production Parameters}

\begin{abstract}
Effect of the electrochemical etching (anodization) that is one of the manufacturing process of porous silicon (PS) on the electrical parameters of metal-porous silicon direct hydrogen cell (Metal-PS-DHC) is considerably high. There is 4 basic anodization parameters of n-type, (111) oriented, single crystal PS fabricated in this study (time, current density, HF ratio and light). 5$100 \mathrm{Min}$. of anodization time, $5-75 \mathrm{~mA} / \mathrm{cm}^{2}$ of current density, 1:1- 1:11 of HF:deionized $\mathrm{H}_{2} \mathrm{O}$ ratio and 1000-7000 lux light intensity is applied. The best anodization time is 40 minutes and corresponding Metal-PS-DHC electrical cell parameters are $\mathrm{Voc}=590 \mathrm{mV}$ and Isc $=30 \mu \mathrm{A}$. The best HF: $\mathrm{H} 2 \mathrm{O}$ ratio is 1:3 and the corresponding Metal-GS-DHP electrical cell parameters are Voc $=540 \mathrm{mV}$ and Isc $=18 \mu \mathrm{A}$. The best light intensity is 4000 lux and the corresponding MetalGS-DHP electrical cell parameters are $\mathrm{Voc}=540 \mathrm{mV}$ and $\mathrm{Isc}=18 \mu \mathrm{A}$. As the experimental results show, Metal-GS-DHP electrical cell parameters are directly related to the anodization conditions.
\end{abstract}

\section{GİRIŞ (INTRODUCTION)}

Gözenekli silisyum, nanometre mertebesinden mikrometre mertebesine kadar değişen boyutlarda boşluklarla çevrelenmiş, silisyum bölgelerden oluşan bir ağdır. Gözenekli Silisyum (GS), Silisyumun hidroflorik asit içinde elektrokimyasal aşındırılması sırasında 1956'da keşfedilmiştir [1]. Gözenekli silisyumun, oda sicaklığında fotolüminesans vermesi nedeniyle bir aday malzeme olarak elektronik cihazların üretiminde kullanılması düşünülmektedir [2]. Dikkate değer bu eğilim, gözenekli silisyum hakkındaki araştırmaları arttırmıştır. 
$\mathrm{Bu}$ çalışmada, Hidroflorik asit (HF) içinde elektrokimyasal aşındırma yöntemi ile (anodizasyon) elde edilen gözenekli silisyum, HF konsantrasyonu, sıcaklık, iletkenlik tipi, ş̧ınlama ve anodizasyon zamanı, akım yoğunluğu gibi etkenler değiştirilerek incelenmiştir [3]. Bu etkenlerin, gözenekli silisyumun, hacmine, kalınlığına, gözenekliliğine ve fotolüminesansına nasıl yansıdığı araştırılmıştır. GS Kristal yapısının gözenekliliği, metal-GS eklemlerin gaz sensörleri gibi kullanılmasına yeni bir perspektif açar [4]. Su buharının ortamda bulunması, Si-Si ile Si-H bağlarının kırılmasına yada oluşmasına neden olur. Balagurov vd. 1996 yılında yaptıkları çalışmalarda su buharının gözenekli silisyumun fotolüminesans spektrumunun üzerindeki etkisini analiz etmiştir [5]. Bu nedenle, nemin etkisi ile Au-GS eklemlerinin I-V karakteristiklerinin değişimi gözlenmiştir [6-7-8]. Ayrıca, HF oran1 ve akım yoğunluğunun mezo gözenekli sislisyumun gözenekliliğine ve yüzey alanına etkileri incelenmiştir [9]. Das ve arkadaşları, akım yoğunluğunun metal-GS yapının optik ve bariyer yüksekliği parametrelerine etkisini incelemişlerdir [10-11]. Yine akım yoğunluğunun gözenekli silisyum kalınlığına ve üzerinde büyütülecek kuantum dotlara etkisi gözlenlenmiştir [12]. Anodizasyon zamanının GS'nin yapısal parametrelerine ve fotolüminesansına etkisi gösterilmiştir [13]. Son olarak, anodizasyon zamanının güneş pili parametrelerine etkisi incelenmiştir [14].

\section{DENEYSEL (EXPERIMENTAL)}

\subsubsection{Gözenekli Sílisyum Üretimi (Production of Porous Silicon)}

Tek kristal, n-tipi, (111) yönelim ve $1 \times 10^{-2} \Omega \mathrm{cm}$ özdirençli (Sb katkılı) silisyum kullanıldı. Elektrokimyasal aşındırma (anodizasyon) işleminde 4 parametre etkindir. Bunların ayrı ayrı etkilerinin incelenebilmesi için diğer 3 parametrenin sabit tutulması gereklidir. Daha önceki çalışmalarımız göz önünde bulundurularak şu sabit parametreler kullanılmıştır [15]. Anodizasyon zamanı 40 dakika, akım yoğunluğu $15 \mathrm{~mA} / \mathrm{cm}^{2}, \mathrm{HF}: \mathrm{dH}_{2} \mathrm{O}$ oranı 1:3 ve 1şı aydınlatma şiddeti 5000 lüx'dür.

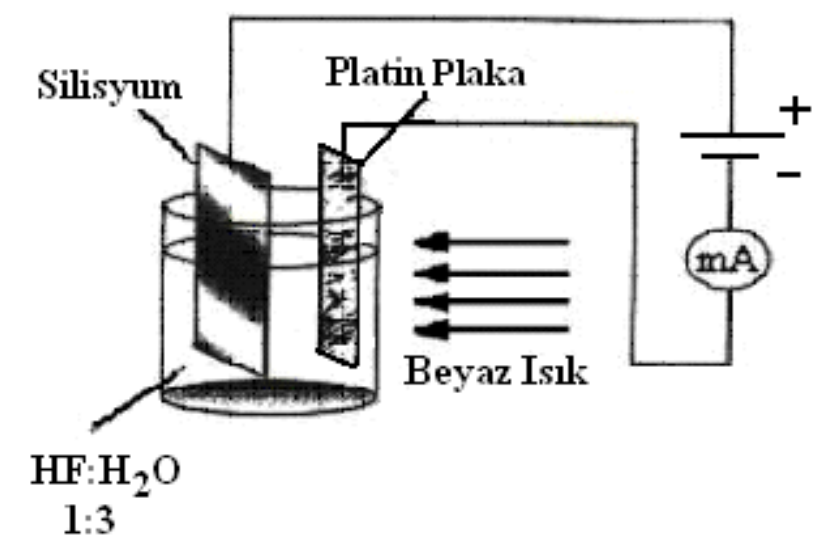

Şekil 1. GS tabakanın Si yüzey bölgesinde elde edilmesi için kullanılan elektrokimyasal anodizasyon düzeneği.

Elektrokimyasal anodizasyonda silisyum anot, platin plaka ise katot görevi yapar (Şekil 1). Deneye başlamadan önce silisyum kristalinin parlak yüzeyi standart RCA prosedürü ile temizlendi. Beyaz 1şık (75 mW.cm-2 halojen lamba) parlak yüzeye doğru olacak şekilde kaba yerleştirildi.

\subsubsection{Metal-GS-DHP Üretimi (Production of Metal-PS-DHC)}


GS-Si edildikten sonra vakumda, elektron-demeti buharlaştırma yöntemi kullanılarak, vakum sisteminde (Şekil 2.a) GS filmlerin üzerine Au metali $(150 \mathrm{~nm})$ kaplandı. Filmlerin kalınlığ 1 "Deposition Controller (Inficon, Leybold)" cihazı ile buharlaştırma esnasında ölçüldü. Metal-GS-DHP ifadesinde "Metal" olarak kastedilen bu altın metalidir. Bu metal Proton Exchance Membran (PEM)'deki ayırıcı tabaka gibi işleve yardımcı olur. Elektriksel ölçümlerin gerçekleştirilebilmesi için Şekil 2.b'de gösterildiği gibi silisyum yüzeye (arka yüzey) indiyum, GS metal $(\mathrm{Au})$ kaplı yüzeye ise nokta gümüş kontak (elektriksel bağlantı için) yapıldı. Bu kontaklardan yararlanılarak I-V karakteristikleri "Keithley 617 Electrometer" ve bilgisayar bağlantısı için GPIB kart kullanılmıştır. Farklı ortamlarda Voc açık devre gerilimi Isc kısa devre akımı 'Thurlby' 1503 digital multimeter" belirlendi. GS'nin mikroyapı fotoğrafları Nicon Eclipse MA100 görüntü analiz cihazı ile elde edilmiştir.

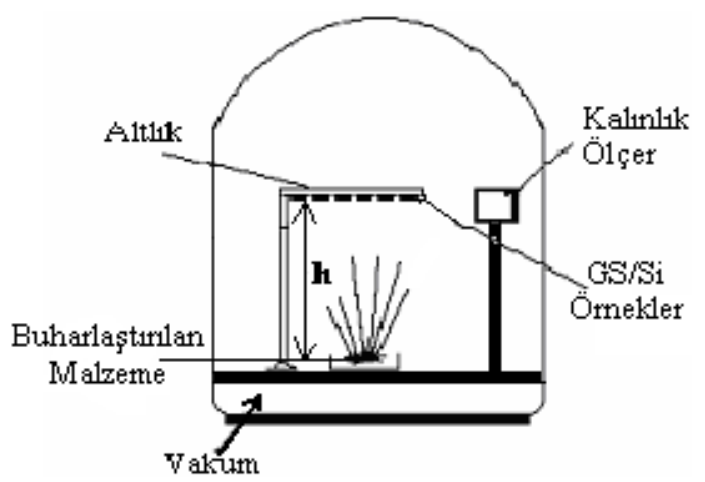

(a)

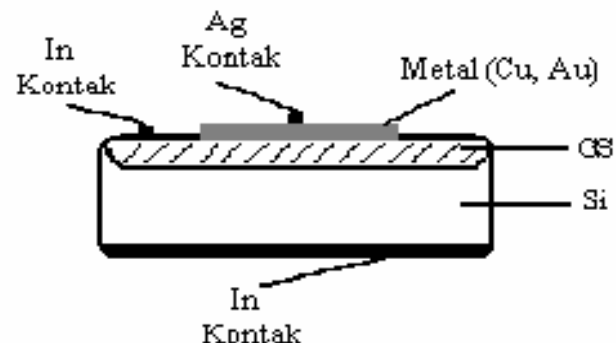

(b)

Şekil 2. a) GS-Si yapının yüzeyine metal kaplamak için kullanılan vakum sistemi,

b) Metal-GS-Si Schottky eklemindeki kontaklar.

\section{BULGULAR VE TARTIŞMA (RESULTS and DISCUSSION)}

Hidrojen pili mekanizması uzun yıllardır bilinen bir teknolojidir. Günlük hayatımıza uygulanamamasının birkaç önemli sebebi vardır. Hidrojen doğada saf halde bulunmaz, üretilmesi için bir enerji harcanmalıdır. Yani hidrojen enerjinin kullanımı başka bir enerji kaynağına bağlıdır. Üretiminden sonra saklanması ve taşınmasındaki riskler bu teknolojinin zorluklarındandır.

$\mathrm{Bu}$ nedenle son yıllardaki araştırmalarda doğrudan hidrojen pili büyük önem arz eder. Bu teknolojinin hedefi hidrojeni saf olarak kullanmak yerine hidrojen içerikli sıvıları kaynak olarak kullanmaktır. MetalGS-DHP de bunlardan biridir. Bu yapı hidrojen içerikli yapıların içine yerleştirildiğinde bir potasiyel fark üretir [16]. GS yapı, proton exchance mebrandaki (PEM) membran görevini görür. Sıvının içindeki hidrojenin ayrışmasını ve yapının alt kısma ulaşmasını sağlar. Metal-GS-DHP üzerine gelen su molekülleri $\left(\mathrm{H}_{2} \mathrm{O}\right)$ parçalanır.

$$
\begin{gathered}
2 \mathrm{H}_{2} \mathrm{O} \longrightarrow 2 \mathrm{H}_{2}+\mathrm{O}_{2} \\
\mathrm{H}_{2} \rightarrow 2 \mathrm{H}^{+}+2 e^{-}
\end{gathered}
$$

Veya diğer bir reaksiyon da suyun proton $\left(\mathrm{H}^{+}\right)$ve $\mathrm{OH}-$ iyonlarına ayrışmasıdır.

$$
\mathrm{H}_{2} \mathrm{O} \rightarrow \mathrm{H}^{+}+\mathrm{OH}^{-}
$$

Her iki reaksiyonda da $\mathrm{O}_{2}$ ve $\mathrm{OH}^{-}$ye göre çok daha küçük boyutlu olan hidrojen iyonları metal filmden geçip Metal/GS ekleme ulaşır. GS film boyunca protonlar $(\mathrm{H}+)$ konsantrasyon gradyanı meydana getirerek sınır bölgesinde dipoller oluşturlar. Bu dipoller açık devre gerilimini meydana getirmektedirler. $\mathrm{Bu}$ potansiyel fark çok yüksek değildir (ortalama $\mathrm{Voc}=500 \mathrm{mV}$, ortalama Isc $=10 \mu \mathrm{A}$ ). Ama bu üretimi 
sağlayan Metal-GS-DHP yapının boyutlarının $1 \mathrm{cmx} 1 \mathrm{~cm} x 0.5 \mathrm{~mm}$ olduğu düşünülürse çalışma oldukça ümit vericidir.

$\mathrm{Bu}$ çalışma, Metal-GS-DHP yapının pil parametrelerinin verimli hale getirilmesi ile ilgilidir. GS yapının boşluk kapasitesi ve yüzey morfolojisi tamamıyla üretim şartlarına bağlıdır. Bu nedenle anodizasyon şartları değiştirilerek Metal-GS-DHP yapının pil parametrelerinin iyileştirilmesi hedeflenmiştir.

Şekil 3.a)'da bir Metal-GS-DHP yapının örnek bir I-V karakteristiği görülmektedir. Yapısı itibarıyla Schottky diyota benzer. Şekil 3.a)'da 1. $\mathrm{HF}: \mathrm{dH}_{2} \mathrm{O}$ oran1, 2. Iş1k aydınlatma şiddeti, 3. Zaman, 4.Akım yoğunluğu olmak üzere; Tablo 1 de gösterilen en iyi parametrelere aittir. Ancak ayrıntılı incelemesinde, klasik bir güneş pili penceresine benzer bir pencereye sahiptir (Şekil 3.b). Pencerenin kesim yerleri Voc ve Isc değerlerine karşılık gelmektedir. Şekil 3.b)' de yine, 1. $\mathrm{HF}: \mathrm{dH}_{2} \mathrm{O}$ oranı, 2. Işık aydınlatma şiddeti, 3. Zaman, 4.Akım yoğunluğu olmak üzere; Tablo 1 de gösterilen en iyi parametrelere aittir. Ayrıca Voc ve Isc değerleri Metal-GS-DHP yapının alt ve üst kontakları arasında bir ölçüm aleti ile de direkt olarak belirlenebilmektedir.

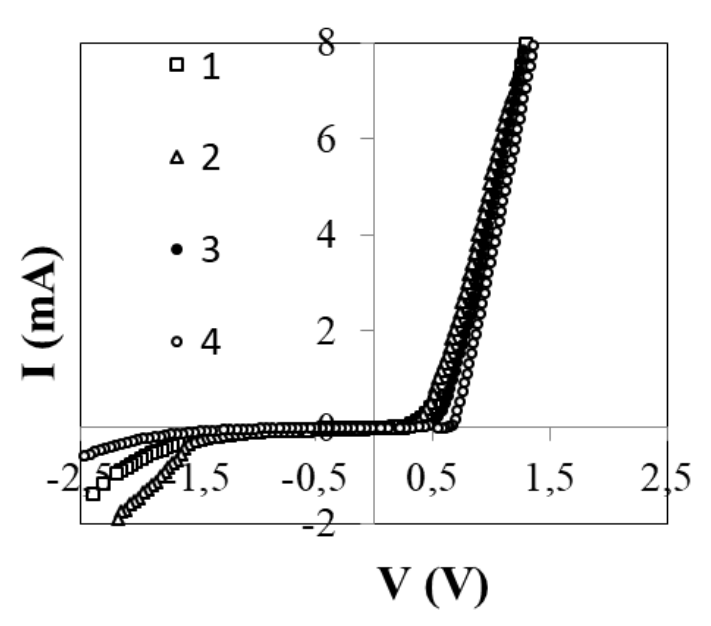

(a)

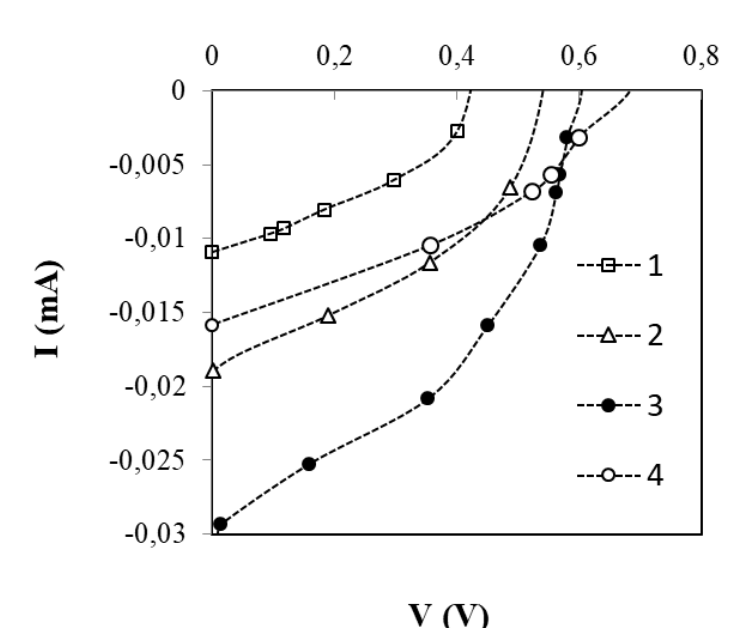

(b)

Şekil 3. a) Metal-GS-DHP I-V karakteristiği, b) Bu I-V karakteristiğinin penceresi. (1. $\mathrm{HF}: \mathrm{dH}_{2} \mathrm{O}$ oranı, 2. Iş̧ aydınlatma şiddeti, 3. Zaman, 4.Akım yoğunluğunun en iyi örnekleri).

\subsubsection{Anodizasyon Zamanı (Anodization Time)}

Anodizasyon süresi 5-10-25-40-70-100 dakika olarak değiştirilirken; akım yoğunluğu $15 \mathrm{~mA} / \mathrm{cm}^{2}$, $\mathrm{HF}: \mathrm{dH}_{2} \mathrm{O}$ oranı 1:3 ve 1şı aydınlatma şiddeti 5000 lüx'de sabit tutulmuşur. Bu şartlarda üretilen GS yapıların imaj analizör görüntüleri Şekil 4'deki gibidir. Bu görüntüler incelendiğinde 5 ve 10 dakika sonuçları oldukça benzerdir. Si yüzeyi oldukça küçük parçacıklar halinde bozulmaya başlamıştır. Sonraki anodizasyon zamanlarında süreyle doğru orantılı bir biçimde GS yapıda meydana gelen boşluklar büyümeye başlamıştır. 


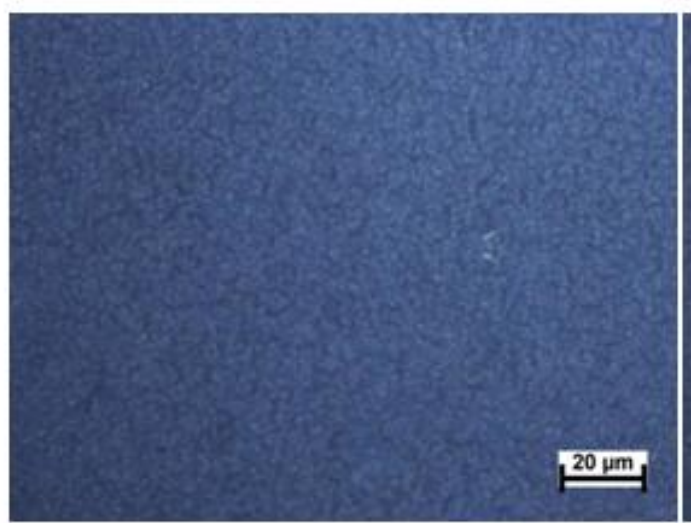

a)

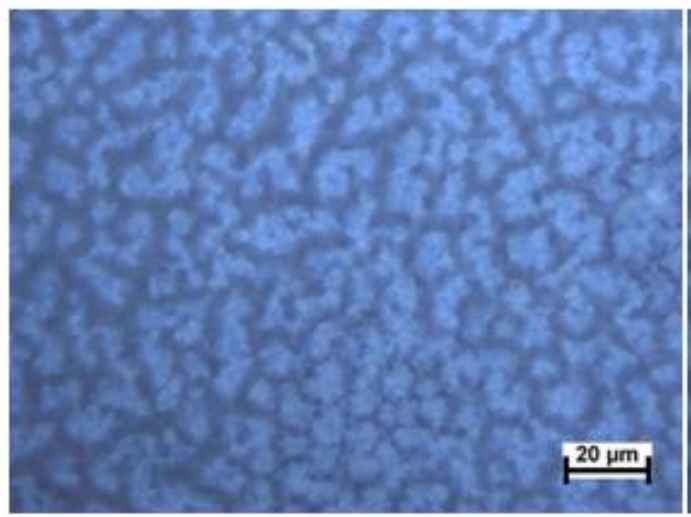

c)

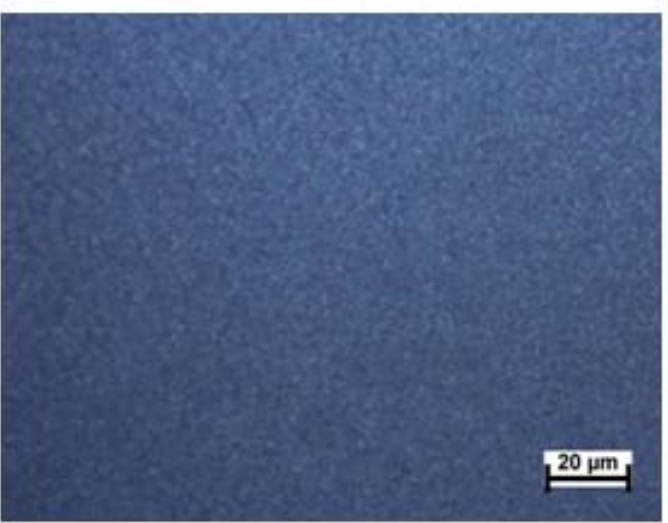

b)

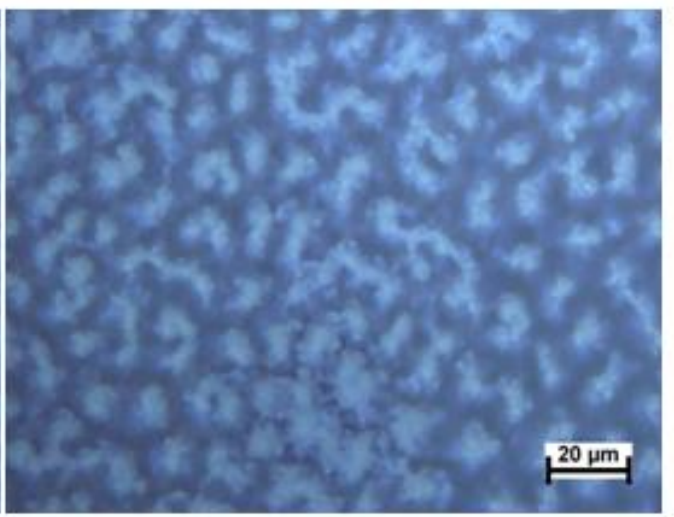

d)

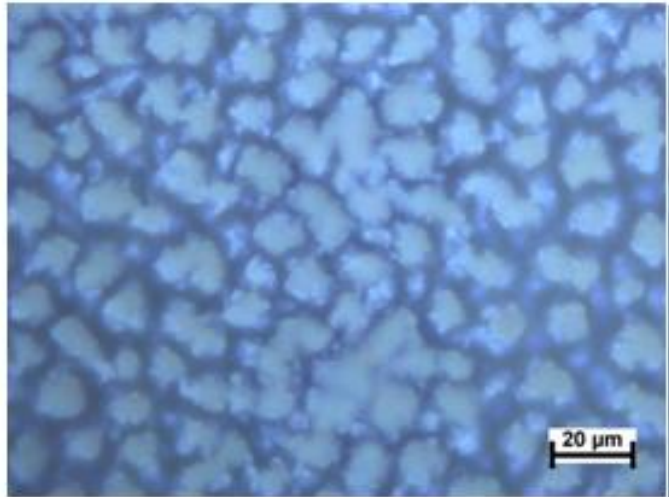

e)

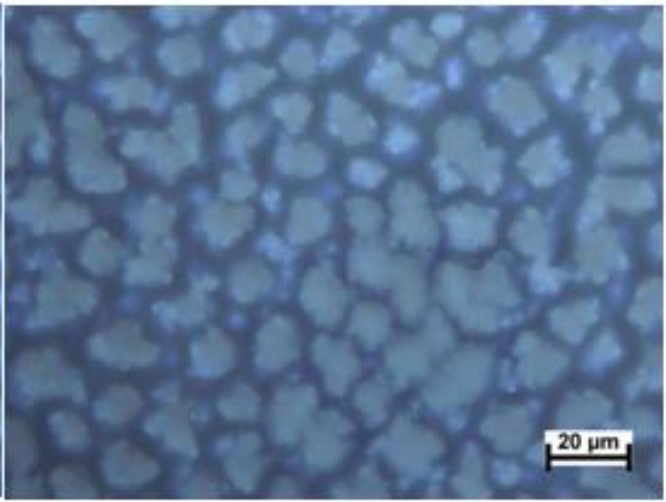

f)

Şekil 4. Anodizasyon süreleri sırasıyla a) $5 d k$, b) $10 d k$, c) $25 d k$, d)40dk e) $70 d k, f) 100 d k$ 'dır.

Bu anodizasyon sürelerinde üretilmiş GS'den elde edilen Metal-GS-DHP yapının Voc ve Isc elektriksel parametreleri Şekil 5.a) ve b) 'deki gibidir. Düşük anodizasyon sürelerinde $(5,10,25 \mathrm{dk})$ yüzeyde bağlar yeni kırılmaya başlanmıştır. Hidrojen iyonu birikimi için yeterince boşluk oluşamamıştır. Elektriksel parametrelerin en yüksek olduğu anodizasyon zamanı 40 dakikadır $(\mathrm{Voc}=590 \mathrm{mV}$ ve Isc $=30 \mu \mathrm{A}) . \mathrm{Bu}$ sürede gözenek boyutları ve toplam boşluk miktarı uygun hale gelmiştir. Süre daha çok arttığında boşluk çapları ve miktarı olması gerekenden daha fazla artmış ve yapı hidrojen iyonlarını sudan ayırmakta başarısız olmaya başlamıştır. 


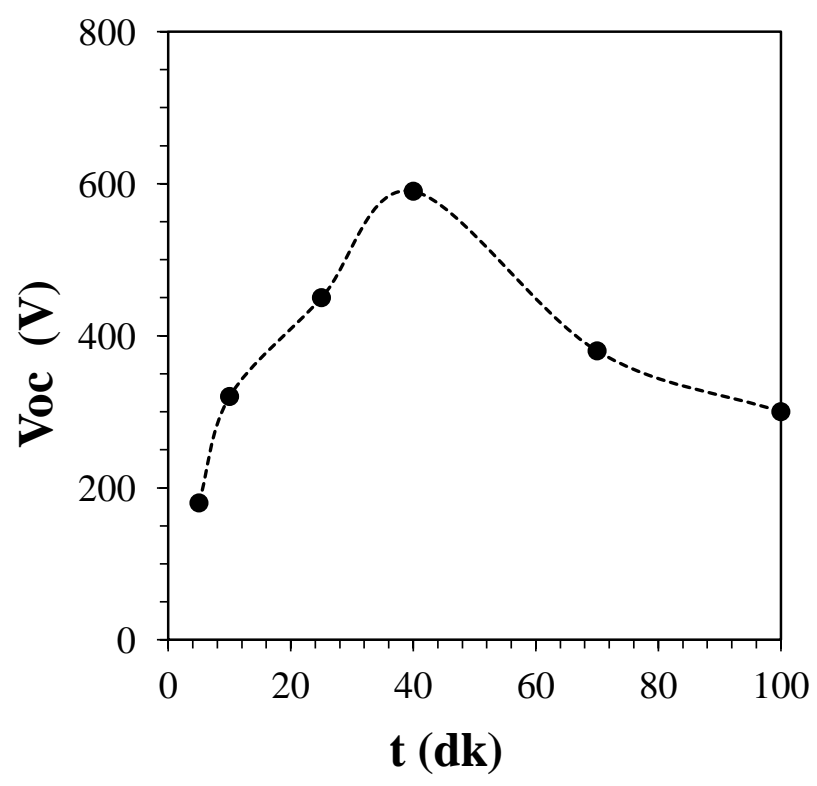

a)

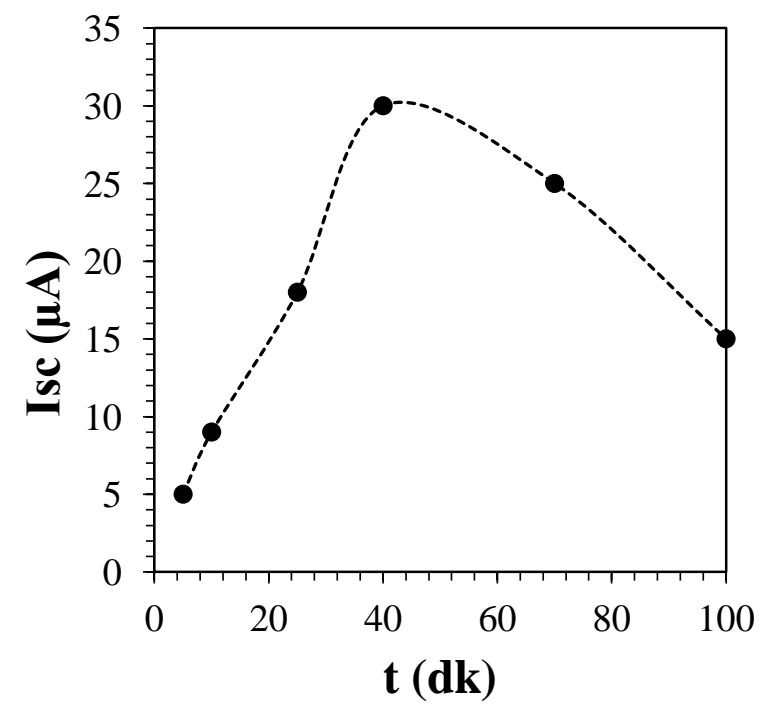

b)

Şekil 5. Değişen anodizasyon sürelerinde a) Açık devre gerilimi b) Kısa devre akımı.

\subsubsection{Akım Yoğunluğu (Current Density)}

Uygulanan Akım Yoğunluğu 5,10,20,30,50,75 mA/cm² olarak değiştirilirken; anodizasyon zamanı 40 dakika, $\mathrm{HF}: \mathrm{dH}_{2} \mathrm{O}$ oranı 1:3 ve 1şı aydınlatma şiddeti 5000 lüx'de sabit tutulmuştur (Şekil 6). Düşük akım yoğunluklarında GS oluşumu yeni başlarken, akım yoğunluğunun şiddeti arttıkça gözeneklilik de artmıştır. 

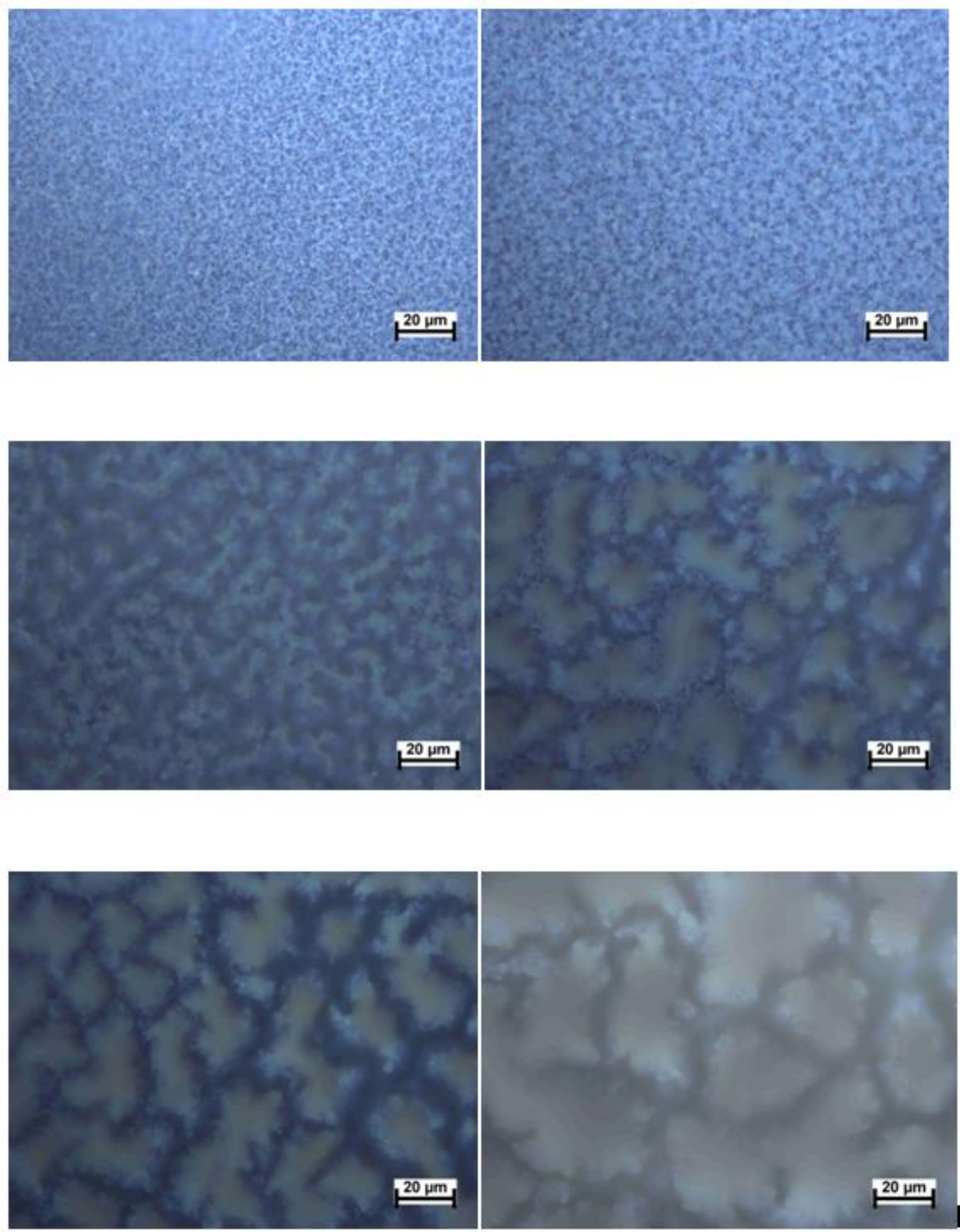

Şekil 6. Akım yoğunluklart sirasıly a a) $5 \mathrm{~mA} / \mathrm{cm}^{2}$, b) $10 \mathrm{~mA} / \mathrm{cm}^{2}$, c) $20 \mathrm{~mA} / \mathrm{cm}^{2}$, d) $30 \mathrm{~mA} / \mathrm{cm}^{2}$ e) 50 $\left.\mathrm{mA} / \mathrm{cm}^{2}, \boldsymbol{f}\right) 75 \mathrm{~mA} / \mathrm{cm}^{2}$ 'd $l r$.

Bu akım yoğunluklarında üretilmiș GS'den elde edilen Metal-GS-DHP yapının Voc ve Isc elektriksel parametreleri Şekil 7.a) ve b) 'deki gibidir. Düşük akım yoğunluklarında $\left(5,10 \mathrm{~mA} / \mathrm{cm}^{2}\right)$ yüzeyde bağlar yeni kırılmaya başlanmıştır. Hidrojen iyonu birikimi için yeterince boşluk oluşamamıştır. Elektriksel parametrelerin en yüksek olduğu akım yoğunluğu $20 \mathrm{~mA} / \mathrm{cm}^{2}$, $\operatorname{dir}(\mathrm{Voc}=700 \mathrm{mV}$ ve Isc $=15 \mu \mathrm{A})$. Bu akım 
yoğunluğunda gözenek boyutları ve toplam boşluk miktarı uygun hale gelmiştir. Akım yoğunluğu daha çok arttığında boşluk çapları ve miktarı olması gerekenden daha fazla artmış ve yapı hidrojen iyonlarını sudan ayırmakta başarısız olmaya başlamıştır.

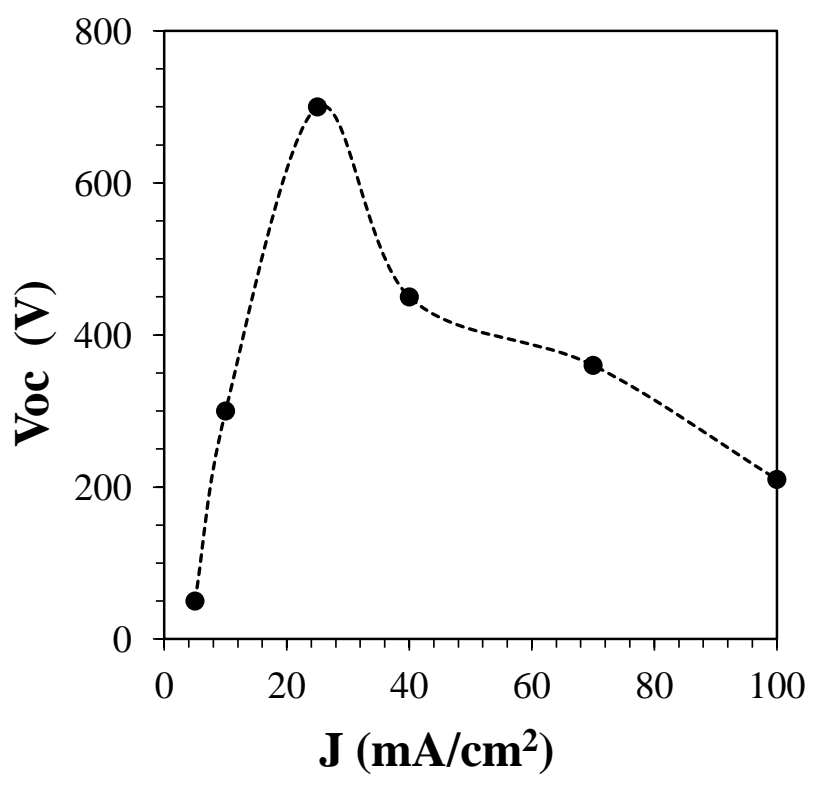

a)

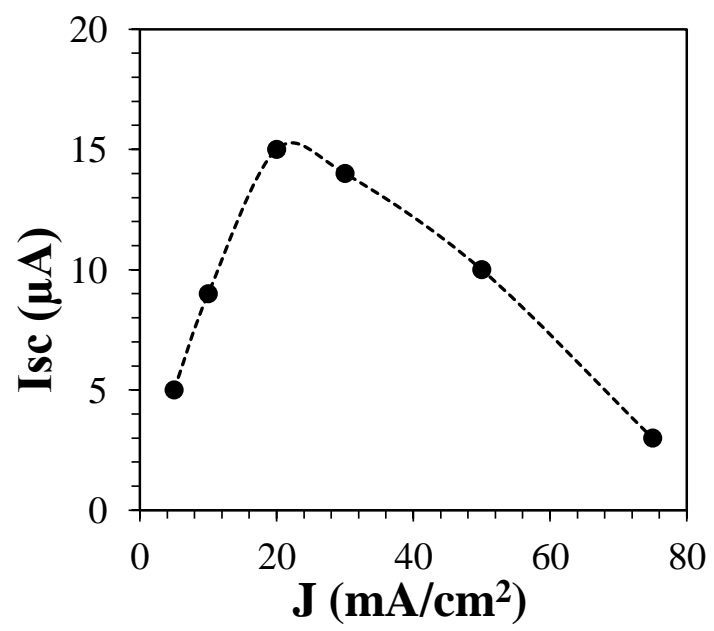

b)

Şekil 7. Değişen akım yoğunluklarında a) Açık devre gerilimi b) Kısa devre akımı. 


\subsubsection{HF:dH $\mathrm{dH}_{2} \mathrm{Oranı}\left(\mathrm{HF}: \mathrm{dH}_{2} \mathrm{O}\right.$ Ratio)}

$\mathrm{HF}: \mathrm{dH}_{2} \mathrm{O}$ çözeltisi oranı 1:1, 1:3, 1:5, 1:7, 1:9, 1:11 olarak değiştirilirken; anodizasyon zamanı 40 dakika, akımyoğunluğu $15 \mathrm{~mA} / \mathrm{cm}^{2}$ ve sşık aydınlatma şiddeti 5000 lüx'de sabit tututlmuştur. Karışımdaki HF oranı azaldıkça gözenek boyutları küçülmüştür.
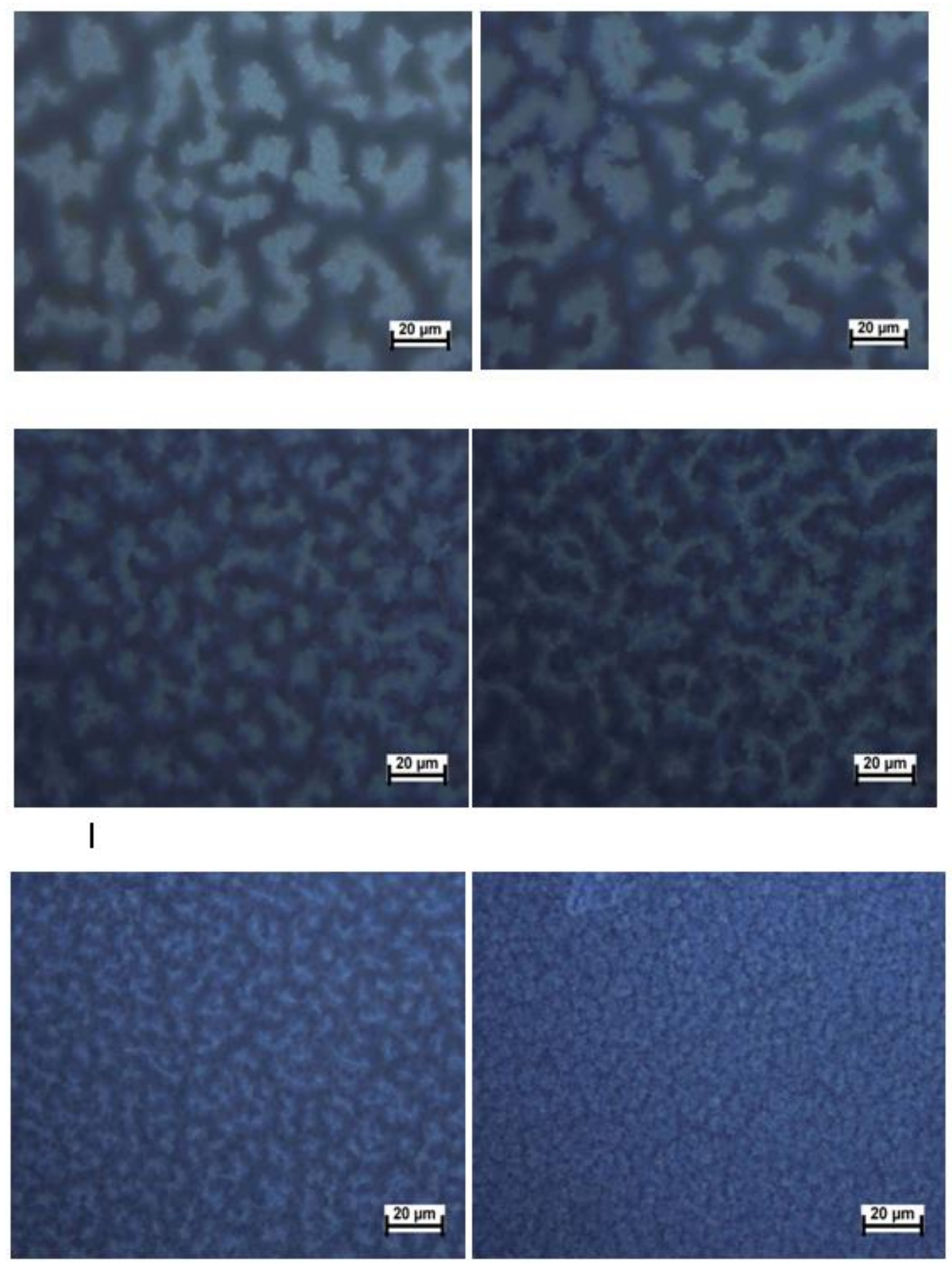

Şekil 8. $\mathrm{HF}: \mathrm{dH}_{2} \mathrm{O}$ çözeltisi oranı sırasıyla a) 1:1, b) 1:3, c) 1:5, d) 1:7, e) 1:9, f) 1:11 'dir. 
$\mathrm{Bu} \mathrm{HF}: \mathrm{dH}_{2} \mathrm{O}$ çözeltisi oranlarında üretilmiş GS'den elde edilen Metal-GS-DHP yapının Voc ve Isc elektriksel parametreleri Şekil 9.a) ve b) 'deki gibidir. Sonuçlar önceki anodizasyon koşullarına benzerdir. Elektriksel parametrelerin en yüksek olduğu $\mathrm{HF}: \mathrm{dH}_{2} \mathrm{O}$ çözeltisi oranı 1:3'dür. (Voc $=420 \mathrm{mV}$ ve Isc $=10$ $\mu \mathrm{A})$.

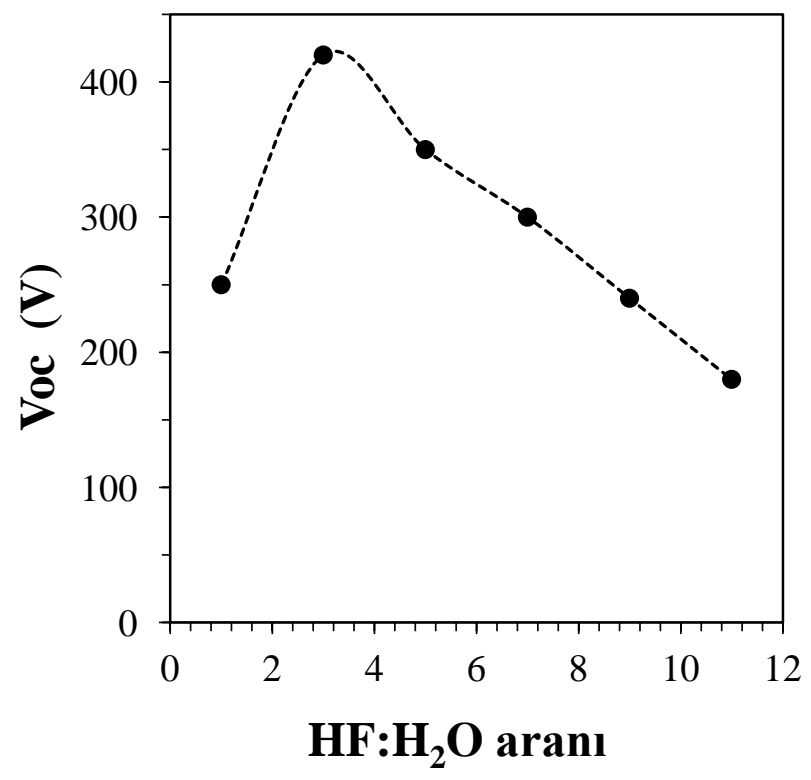

a)

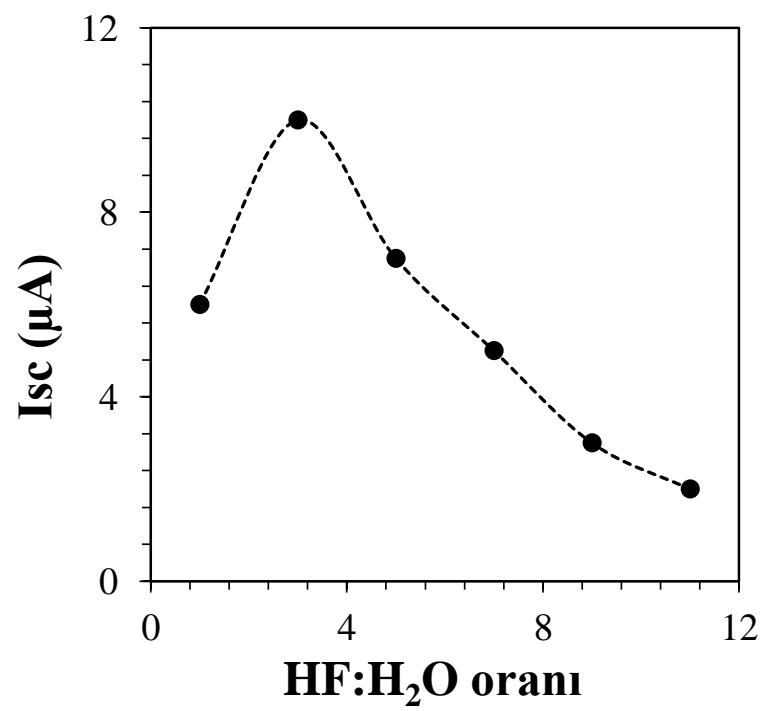

b)

Şekil 9. Değişen $\mathrm{HF}: \mathrm{dH}_{2} \mathrm{O}$ çözeltisi oranlarında a) Açık devre gerilimi b) Kısa devre akımı. 


\subsubsection{Işık Aydınlatma Şiddeti (Light Intensity)}

Işı aydınlatma şiddeti 1000,2000,4000,5000,7000 lüx olarak değiştirilirken; anodizasyon zamanı 40 dakika, akımyoğunluğu $15 \mathrm{~mA} / \mathrm{cm}^{2}, \mathrm{HF}: \mathrm{dH}_{2} \mathrm{O}$ oranı 1:3 olarak sabit tutulmuştur. 1000 lüx'de daha çok örümcek ağına benzer bir yüzey oluşurken, 1şık aydınlatma şiddeti arttıkça beklediğimiz morfojolojiye benzer bir yapı oluşmaya başlamıştır.
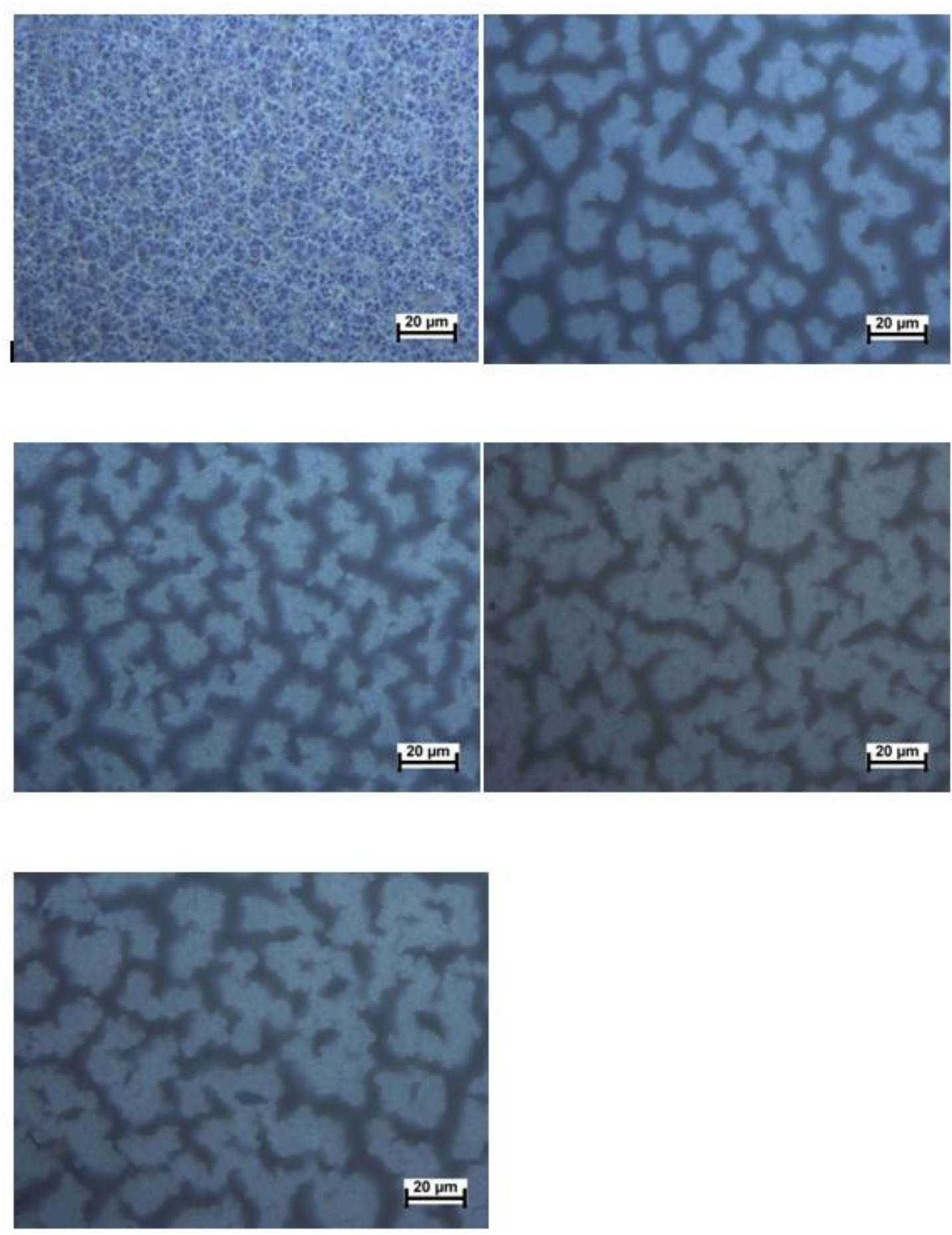

Şekil 10. Işık aydınlatma şiddeti sırasıyla a) 1000 lüx, b) 2000 lüx, c) 4000 lüx, d) 5000 lüx, e) 7000 lüx'dür. 
$\mathrm{Bu}$ 1şık aydınlatma şiddeti oranlarında üretilmiş GS'den elde edilen Metal-GS-DHP yapının Voc ve Isc elektriksel parametreleri Şekil 11.a) ve b) 'deki gibidir. Sonuçlar diğer anodizasyon koşullarona benzerdir. Elektriksel parametrelerin en yüksek olduğu 1şık aydınlatma şiddeti 4000 lüx'dür (Voc= $540 \mathrm{mV}$ ve Isc $=18 \mu \mathrm{A}$ ).

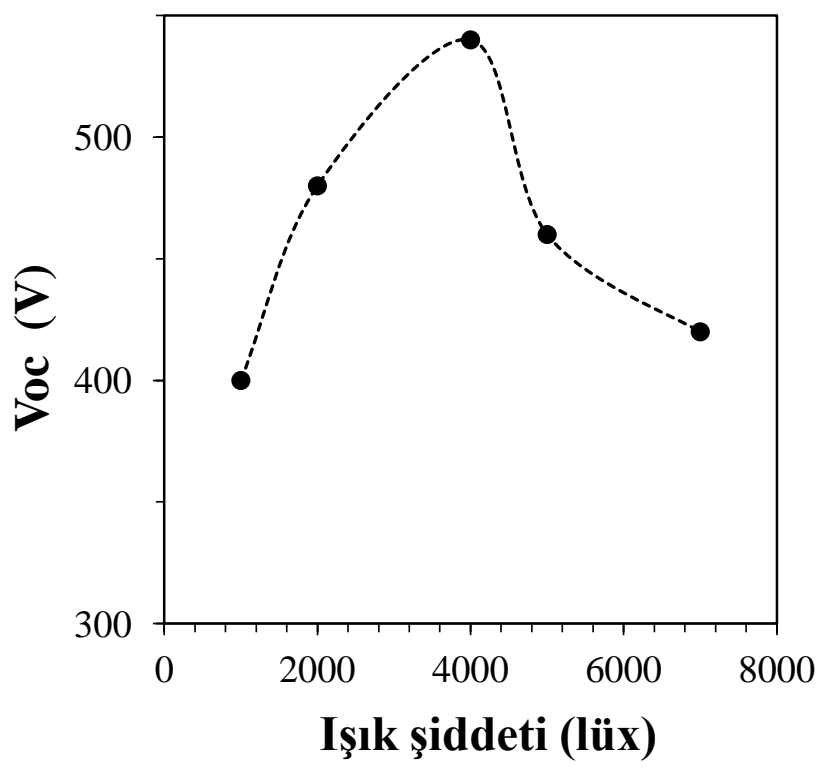

a)

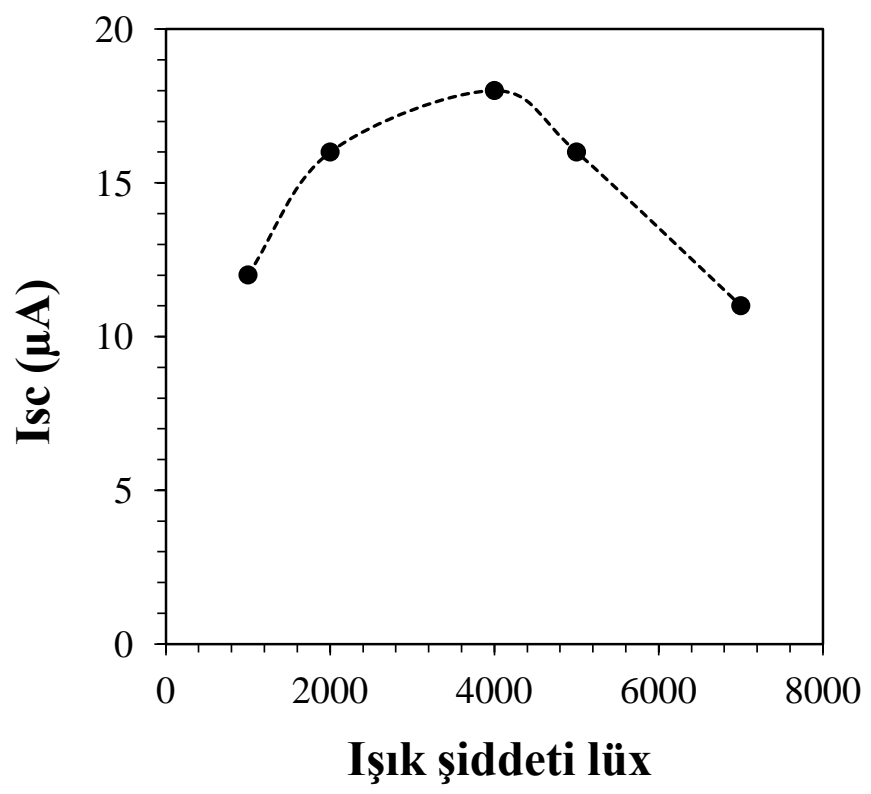

b)

Şekil 9. Değişen ışık aydınlatma şiddeti oranlarında a) Açık devre gerilimi b) Kısa devre akımı.

Anodizasyon koşullarının en iyi değerleri Tablo 1 de özetlenmiştir. Açık devre geriliminde akım yoğunluğunun, kısa devre akımında ise zamanın daha etkin olduğu gözlenmektedir. 
Tablo 1. Anodizasyon koşullarının en iyi elektriksel parametreleri

\begin{tabular}{|l|c|c|c|c|}
\hline & Zaman & Akım Yoğunluğu & $\mathrm{HF}: \mathrm{dH}_{2} \mathrm{O}$ oran1 & $\begin{array}{c}\text { Işık Aydınlatma } \\
\text { Şideeti (lüx) }\end{array}$ \\
\hline En iyi değerler & $40 \mathrm{dk}$ & $20\left(\mathrm{~mA} / \mathrm{cm}^{2}\right)$ & $1: 3$ & 4000 (lüx) \\
\hline Voc $(\mathrm{mV})$ & 590 & 700 & 420 & 540 \\
\hline Isc $(\mu \mathrm{A})$ & 30 & 15 & 10 & 18 \\
\hline
\end{tabular}

\section{SONUÇ (CONCLUSION)}

$\mathrm{Bu}$ çalışmada, GS üretim yöntemi olan anodizayon şartlarının Metal-GS-DHP'in elektriksel parametrelerine etkisi incelenmiştir. Temel amaç, Metal-GS-DHP'in elektriksel parametrelerini arttırmaktır ve bundan sonar üretilecek pillerin üretim koşullarına 1şık tutmaktır. Anodizasyon zamanı (5$100 \mathrm{dk})$, akım yoğunluğu $\left(5-75 \mathrm{~mA} / \mathrm{cm}^{2}\right), \mathrm{HF}: \mathrm{dH}_{2} \mathrm{O}$ oranı $(1: 1-1: 11)$ ve $1 s ̧ 1 \mathrm{k}$ aydınlatma şiddeti (10007000 lüx) aralıklarında değiştirilerek Metal-GS-DHP üretilmiştir. Gözeneklerin, hidrojen içerikli sıvılardan hidrojen + iyonunu ayırabilmesi ve depo edebilmesinin, bir optimum büyüklük aralığı vardır. İmaj görüntülerinden anlaşılacağı üzere gözenek boyutlarının çok küçük olması durumunda depo alanı azdır. Gözeneklerin aşırı büyüme durumunda ise moleküller için GS düz yüzeye benzer ve $\mathrm{H}+$ ayrıştırma işlevini gerçekleştiremez. Metal-GS-DHP'in en iyi anodizasyon koşulları ve elektriksel parametreleri Tablo 1'de görülmektedir. Elde edilen tüm sonuçlar, anodizasyon üretim koşullarının Metal-GS-DHP'in elektriksel parametreleri üzerinde etkin olduğunu göstermiştir.

\section{KAYNAKLAR (REFERENCES)}

[1] A. Uhlir, Electrolytic Shaping of Germanium and Silicon. Bell System Tech. J. 35: (1956) 33-347.

[2] L.T. Canham, Quantum Wire Array Fabrication by Electrochemical and Chemical Dissolution of Wafers. Appl. Phys. Lett. 57:10 (1990) 1046-1048.

[3] R.L. Smith, S.D. Collins, Porous Silicon Formaton Mechanisms. Journal Appl. Phys. 71:R (1992) 121.

[4] A. Faucaran, F. Paskal-Delnnoy, A. Giani, A. Sackda, P. Combette, A. Boyer, Porous Silicon Layers Used for Gas Sensor Applications. Thin Solid Films. 297: (1997) 317-320.

[5] L.A. Balagurov, S.C. Bayliss, A.F. Orlov, E.A. Petrova, B. Unal, D.G. Yarkin, Electrical Properties of Metal/Porous Silicon/p-Si Structures Whit Thin Porous Silicon Layer., Journal of Appl. Phys. 90:8 (2001) 4184-4190.

[6] D. G. Yarkin, (2003), Impedance of Humidity Sensitive Metal/Porous Silicon/n-Si Structures. Sensors and Actuators B. 107: (2003)1-6.

[7] T.D. Dzhafarov, C. Oruc, ve S. Aydin, Humidity-Voltaic Characteristics of Au Porous Silicon Interfaces. J. Phys. D: Appl. Phys. 37, 3: (2004) 404-408.

[8] D. B. Dimitrov, Current-Voltage Characteristics of Porous-Silicon Layers. Physical Review B. 51,3: (1995) 1562-1566. 
[9] P.M.Z. Hasan, V.K. Sajith, M. Shahnawaze Ansari, J. Iqbal, A. Alshahrie, Influence of HF Concantration of Current Density of Characteristic Morphological Features of Mezoporous Silicon. Micropororus And Mezoporous Materials. 249: (2017) 176-190.

[10] M. Das, P. Nath, D. Sarkar, Influence of Etching Current Density on Microstructural Optical and Electrical Properties of Porous Silicon (PS):n-Si Heterostructure. Superlattices and Microstuctures. 90: (2016) 77-86.

[11] M. Ramesh, H.S. Nagaraja, Effect of Current Density on Morphological Structural and Optical Properties of Porous Silicon. Materials Today Chemistry. 3: (2017) 10-14.

[12] F. S. Gill, V. Panvar, H. Gupta, G. S. Kalra, S. Chawla, R. Kumar, R. M. Mehra, Study of Growth Dot and Column inPorous Silicon Samples of Various Thicnesses Prepared at a Costant Current Density. Physica E. 73: (2015) 110-115.

[13] M. Ramesh, H.S. Nagaraja, The Effect of Ethcing Time on Structural Properties of Porous Siliconat The Room Temperature. Material Today: Proseeding. 3: (2016) 2085-2090.

[14] A.S. Khaldun, O. Khalid, Z. Hassan, The Effect of Ethcing Time of Porous Silicon Solar Cell Performance. Superlattices and Microstuctures. 50: (2011) 647-658.

[15] T. D. Dzhafarov, B. Can Omur, C. Oruc. Z.A. Allahverdiev, Hydrojen Sensing Characteristics of CuPS-Si Structures. J. Phys. D: Appl. Phys. 35: (2002) 3122-3126.

[16] C. Oruc, S. Guler, Effect of Au, Ag and Cu Thin Films' Thickness on The Electrical Parameters of Metal-Porous Silicon Direct Hydrogen Fuel Cell. International Journal of Hydrogen Energy. 39: (2014) 20183-20189 